\title{
PESQUISA EM CONTRACEPÇÃO: OPINIÃO DE PESQUISADORES, SUJEITOS E DEFENSORAS DOS DIREITOS DAS MULHERES
}

\author{
Ellen Hardy*, Silvana Ferreira Bento, Maria José Duarte Osis, Eliana Maria Hebling \\ Trabalho realizado no departamento de Tocoginecologia da Faculdade de Ciências Médicas \\ da Unicamp e Centro de Pesquisas Materno-Infantis de Campinas - Cemicamp, Campinas, SP
}

RESUMO - OBjetivo. Conhecer a opinião de pesquisadores, de mulheres - sujeitos de pesquisa, e de defensoras dos direitos das mulheres sobre o significado de "pesquisa" e "cobaia".

Métodos. Pesquisadores (II), mulheres (18) e defensoras (10) foram entrevistados. 0 estudo foi qualitativo e a análise dos dados foi temática.

RESULTADOs. Os participantes tiveram dificuldade em explicar o que é pesquisa; alguns não conseguiram. Para pesquisadores e maioria das mulheres, sujeitos de pesquisa não são cobaias, porque têm liberdade de escolha. Para a maioria das defensoras, sujeitos são cobaias, ainda que consintam em participar de um estudo.

Conclusöes. Foi surpreendente a dificuldade dos pesquisadores em explicar o que é pesquisa. As diferentes opinióes sobre o termo "cobaia" refletem a controvérsia sobre seu significado em pesquisa. Seguramente o termo "cobaia" não se aplica à maior parte dos estudos realizados hoje no Brasil, mas os diferentes significados identificados servem para alertar os pesquisadores a prestar atenção aos aspectos éticos de seus estudos.

Unitermos: Pesquisa. Ética. Cobaias humanas. Contracepção.

\section{INTRODUÇÃo}

No Brasil, os grupos organizados de muIheres incorporaram na sua agenda, por volta de 1980, as questões relativas à saúde das mulheres que estavam em discussão, no mundo, desde aproximadamente 1960. Este assunto, bem como os direitos reprodutivos, assumiu um perfil público através de numerosos debates e publicações na mídia e tinha como objetivo promover mudanças na legislação e nas políticas públicas. As tecnologias contraceptivas e a crescente incidência de esterilização eram o foco principal das discussões'. A interrupção pelo Ministério da Saúde, em janeiro de 1986, do estudo com o contraceptivo subdérmico Norplant $\AA^{2}$, que estava sendo realizado em 2 I centros do Brasil, foi o evento que marcou essa época. De fato, esse estudo foi denunciado porque era o único que constava nos registros da Divisão Nacional de Vigilância Sanitária de Medicamentos (DIMED) porque os pesquisadores haviam solicitado autorização para realizá-lo e enviavam relatórios periódicos sobre seu progresso. Ironicamente, o único estudo que estava tentando cumprir a Declaração de Helsinque ${ }^{3}$ e as resoluções ministeriais vigentes na época foi o que pôde ser denunciado, por não haver nenhum outro registrado.

A partir deste fato, os periódicos e jornais diários e semanais passaram a publicar uma série de debates de caráter ético. Os aspectos éticos das pesquisas brasileiras, na área da regulação da fecundidade, foram duramente questionados, principalmente pelos grupos organizados de mulheres. As críticas referiam-se a possíveis falhas nas investigações com contraceptivos ${ }^{4}$ e à pratica de obtenção do consentimento informado, mais especificamente, à falta de humildade cientifica, às relações de poder e aos estereótipos sobre classe, gênero e raça ${ }^{5}$. Os grupos de mulheres acusavam os pesquisadores de utilizarem as mulheres como "cobaias humanas"; alegavam que os pesquisadores que desenvolviam estudos com contraceptivos tiravam vantagem de mulheres pobres, sem instrução e sem poder para questionar ou decidir por si próprias se queriam ou não participar da pesquisa ${ }^{5-9}$. A interrupção dos estudos com o Norplant $\mathbb{R}$ acabou facilitando uma maior participação do Estado nas investigações sobre contraceptivos e promoveu o debate entre pesquisadores, sujeitos das pesquisas, grupos organizados de mulheres e imprensa ${ }^{5}$.
Na época dos estudos, dois documentos brasileiros estavam vigentes, baseados na Declaração de Helsinque, que se referiam a pesquisas com seres humanos. $O$ primeiro era a Resolução Normativa | /78, da Câmara Técnica de Medicamentos ${ }^{10}$, que fazia referência ao "consentimento do paciente para pesquisas terapêuticas", e dizia: "configuram a obediência ao estatuído na declaração de Helsinque, na qual, para as pesquisas terapêuticas, segundo o critério do pesquisador, - consentimento do paciente poderá ser obtido de modo verbal ou por escrito, quando julgado conveniente". O segundo documento era a Portaria $N^{\circ}$ 16, 1985, da DIMED, que instituía, de forma padronizada, o "Termo de Conhecimento de Risco". Este documento deveria ser utilizado para pesquisas com medicamentos não registrados, ou com indicação ainda não aprovada, ou em produtos importados ainda não analisados pela DIMED. O Termo deveria ser assinado pelo sujeito da pesquisa ou seu responsável e também pelo pesquisador principal" ${ }^{\text {. }}$

Mais tarde, um terceiro documento, a Resolução 01/88, foi publicado pelo Conselho Nacional de Saúde' ${ }^{2}$. A Resolução normatizou as pesquisas na área de saúde e não só a pesquisa terapêutica. Nela, o "consentimento pós-informação" foi definido como: "o acordo por escrito mediante o qual o indivíduo objeto 
HARDY E ET AL.

da pesquisa ou, se for o caso, seu representante legal, autoriza sua participação na pesquisa, com pleno conhecimento da natureza dos procedimentos e riscos a qual se submeterá, com a capacidade de livre arbítrio e sem qualquer coação". O consentimento deveria ser assinado pelo indivíduo ou seu representante legal. Em pesquisas consideradas "sem risco", a obtenção do consentimento poderia ser dispensada por um Comitê de Ética (Cap. II, Art 13).

Apesar da existência desses documentos, o comportamento ético de pesquisadores na área da regulação da fecundidade continuou sendo criticado 4,8,13,14. A impressão que se teve ao revisar a literatura pertinente era que esses documentos não haviam sido suficientemente divulgados e não eram conhecidos pelos pesquisadores ${ }^{15}$. As discussões sobre "cobaias" em pesquisas com contraceptivos, geradas pelos grupos organizados de mulheres, repercutiram na população através da mídia ${ }^{4}$. Progressivamente, foi sendo observada uma maior participação da população em geral e dos meios de comunicação nas discussões sobre os termos "pesquisa" e "cobaia"; termos que, em tempos passados, eram mais restritos à comunidade científica.

Foi no âmbito dessas discussões, em que os grupos organizados de mulheres manifestavam-se contra "os abusos à integridade das mulheres, detectados nos serviços de planejamento familiar e na ação de médicos e cientistas responsáveis por novas tecnologias contraceptivas" " que foi realizado um estudo para avaliar a experiência brasileira com o consentimento informado na área da regulação da fecundidade $^{15}$. $O$ presente trabalho apresenta resultados de uma parte deste estudo que trata de conhecer a opinião de pesquisadores, de mulheres que participaram como sujeitos de alguma de suas pesquisas e de defensoras dos direitos das mulheres sobre os conceitos de "pesquisa" e "cobaia".

\section{MÉtodos}

Tratou-se de um estudo exploratório, com metodologia qualitativa. Os sujeitos foram selecionados em três centros de excelência em pesquisas na área de regulação da fecundidade, localizados em diferentes regiões do Brasil. Os contatos iniciais foram realizados com os diretores dos centros, a fim de convidá-los a participar deste estudo. Após aceitar o convite, cada diretor indicou uma pesquisa que estava em andamento ou havia sido finalizada nos últimos 12 meses, e que implicava o uso de um contraceptivo; também indicou pesquisadores e mulheres envolvidas naquela pesquisa. Para garantir o sigilo da identidade dessas mulheres, primeiro foram contatadas por alguém daquele centro, que as convidou a participar deste estudo. Em cada cidade onde se localizavam os centros também foram identificadas e convidadas defensoras dos direitos das mulheres. No total, I I pesquisadores, 18 mulheres e 10 defensoras foram entrevistadas.

Utilizando-se de entrevistas em profundidade, com roteiros específicos para cada uma das três categorias de participantes, procurouse estudar a experiência brasileira com o consentimento informado, baseado na Resolução I/88, ${ }^{12}$ em vigência quando os centros iniciaram as pesquisas. Os três roteiros foram prétestados com pessoas de características semeIhantes às que participariam do estudo e esses resultados não foram incluídos na análise. Os roteiros incluíram as perguntas que foram consideradas para a análise deste trabalho: "Se você tivesse que explicar para o seu filho o que é pesquisa, como explicaria?" e "Algumas vezes a gente ouve dizer na televisão ou lê no jornal que as pessoas que participam de pesquisas são usadas como cobaias. $\bigcirc$ que acha disso?" Para o grupo de mulheres também foi perguntado "Como você imagina que é feita uma pesquisa?" As entrevistas foram individuais, gravadas mediante autorização dos participantes e identificadas apenas por um número. Os pesquisadores e as defensoras foram entrevistados no próprio local onde trabalhavam e as mulheres nos hotéis onde as pesquisadoras se hospedavam, em cada cidade. Esta estratégia facilitou a abordagem das mulheres, permitindo privacidade para o relato de suas experiências.

Para o processamento e análise dos dados, todas as entrevistas foram digitadas na sua íntegra, e a transcrição foi revisada por uma pessoa distinta. A seguir, os textos foram lidos para identificar as variáveis que compunham cada roteiro e categorizar as falas dos sujeitos. Depois, todas as respostas que correspondiam a cada variável foram resumidas, segundo as categorias de respondentes. Esse resumo foi revisado por uma das autoras. Concluídas essas análises parciais, foi elaborado um resumo geral, por variável. Esse processo de análise esteve orientado pelas propostas metodológicas de Wolcott ${ }^{16}$.

$\bigcirc$ protocolo deste estudo foi aprovado pela Comissão de Ética Médica do Hospital das Clínicas da Universidade Estadual de Campinas (Unicamp). Foi obtido o consentimento livre e esclarecido através de um processo que incluiu informação sobre o estudo, esclarecimento de dúvidas e assinatura do Termo de Consentimento. Todos os participantes receberam uma cópia do Termo.

\section{Resultados}

\section{Pesquisa}

Foi difícil para os entrevistados explicar o que é pesquisa. Todos eles procuraram definir o termo, sem que chegassem a uma conceituação clara ou objetiva. Entre os pesquisadores, um respondeu que pesquisa "é a atividade mais gratificante que existe". Outro disse que "seria um conjunto de informações que a gente vai tentar obter de várias pessoas, no caso de pesquisa com humanos, ou da observação de objetos ou de coisas, mas tentando chegara um consenso a respeito daquelas observações que a gente acompanhou, pra tirar resultados a partir daquilo. Ou seja, é observar para concluir, para modificar o que for necessário".

Embora tenha havido um consenso entre os pesquisadores de que era difícil definir ou explicar o que é pesquisa, apenas, um deles apontou isso de forma explícita: "É dentro de uma base não é, você achar uma coisa melhore mais nova, que facilite melhor a vida, então você vai, dentro de um dado você vai pesquisar, trabalhando, trabalhando, trabalhando, até que um resultado que se espera seja o melhor; épor al. Acho isso aí o mais difícil que você perguntou até agora."

Quanto às mulheres, pôde-se observar que também tiveram dificuldades em explicar o conceito de pesquisa. Foi interessante constatar na fala de todas, os balbucios e as palavras desconexas na busca de uma explicação. Quatro não souberam completar o pensamento e chegar a uma tentativa de explicação. As demais fizeram alguma referência de que pesquisa é um estudo que tem o objetivo de melhorar alguma coisa, coincidindo com a opinião dos pesquisadores: "... é um trabalho qu alguém está fazendo para que melhore as condições de um outro alguém ou de outras pessoas, 
sei lá. Pesquisa é uma coisa que as pessoas fazem pra melhorar, sempre pra melhorar, sempre pra procurar um meio melhor das coisas funcionarem".

Algumas mulheres, ao tentarem definir pesquisa, mencionaram algo relacionado à experiência prática que estavam tendo ou tiveram, em participar de um estudo, como por exemplo: "A pesquisa, eu vou dizer o seguinte, que é uma pesquisa que é feita sobre o método $X$, que é uma pesquisa de um método X importado, e que essa pesquisa é muito bem elaborada, porque as pessoas rea/mente se preocupam se você está bem, o que vocêacha, sua opinião, você tem livre e espontânea vontade de perguntar e de falar qualquer coisa sobre esse X."

Além da dificuldade com o conceito de pesquisa, as mulheres não souberam explicar como era feita uma pesquisa. Das 18 entrevistadas, seis declararam que não sabiam. Algumas mencionaram suas próprias experiências como sujeito, por exemplo: ter sido pesada, verificada sua pressão arterial, respondido perguntas. Outras comentaram que se faz pesquisa comparando os efeitos de um método contraceptivo entre as participantes do estudo: " $A$ idéia que eu tenho é esta, ele consulta a gente, cada uma é de um jeito, as lâminas que ele colhe o materialé claro que, élógico que não são iguais, e compara uma e a outra, principalmente que todas usam, no caso, o mesmo método X". Duas referiram que as pesquisas são feitas em animais antes de serem realizadas com pessoas.

Apenas uma das mulheres mencionou a necessidade de um protocolo de pesquisa e de sua aprovação: "Primeiro faz o projeto de pesquisa, não é? Ese é aprovado vai à execução... depende se é no Ministério, se é o diretor do hospital ... a partir do planejamento, tem que delegar cargos e poderàs pessoas que vão exerceresse tipo de trabalho, né, e de preferência a pessoas que se confia, né." Outra mencionou a importância do consentimento da pessoa para participar na pesquisa: "... eu não sei o que se faz primeiro. Ah! Perguntar se aquela pessoa aceita ser pesquisada."

As defensoras, em sua grande maioria, ao explicar seu pensamento sobre o que é pesquisa, mencionaram a necessidade de se fazer pesquisas em contracepção, para que se possa adequar os métodos à nossa população brasileira, e para que se busque novas alternativas que tragam mais segurança e conforto: "... se a gente não faz pesquisa no Brasil, primeiro que a gente sempre importa conceitos e metodologias e coisas que estão baseadas em pesquisas de outras pessoas, em outros lugares, outras realidades, né? [Seria importante] para adequar melhor, pra gente ter um resultado mais satisfatório dos esforços que se faz em qualquer campo de desenvolvimento".

Assim como ocorreu com os pesquisadores e com as mulheres, também ficou evidente a dificuldade das defensoras em definir o que é pesquisa. Uma delas relatou: "Não é uma coisa fácil, acho, de explicar. É, na realidade eu acho ... eu explicaria que é aquilo que a gente faz quando a gente tem curiosidade de conhecer alguma coisa que não se sabe, né? Ou, que se sabe pouco sobre aquilo, né? Eque é, que a gente pode, a partir de uma, de uma observação de uma coisa pequena, localizada, a gente pode entender outras coisas mais importantes, né?"

As defensoras basearam suas respostas sobre o que é pesquisa na busca de conhecimento, na confirmação de hipóteses, e no conhecimento do que não se sabe ou sabe-se pouco, como se observa em alguns dos relatos: "Seria uma possibilidade, uma busca de conhecimento numa determinada área, né?"; "... procurar o porquê das coisas, procurar conhecer melhor as coisas. Investigar para poderdescobrir".

\section{Cobaia}

Quase todos os pesquisadores (10), quando questionados sobre o que achavam da afirmativa de que as pessoas, sujeitos de pesquisa, eram "cobaias", disseram que não concordavam. Embasaram seu ponto de vista na existência do consentimento informado e na liberdade de escolha do indivíduo em participar ou não de uma pesquisa: "Isso é um tabu que foi criado. ... Essa coisa de ser cobaia talvez ainda fosse de uma época que as pessoas não tinham segurança, não existia o consentimento informado, não existia uma credibilidade, né? Acho que a gente está vivendo um momento que a gente pode se dar ao luxo de confiar nas pesquisas."

Outro argumento deles foi que as pesquisas realizadas no Brasil não incluem as fases iniciais da experimentação clínica: "... só se vai começara fazer pesquisa no ser humano depois que você tem uma pesquisa amplamente realizada a nível laboratorial, ou mesmo com animais, de doses tóxicas de alguns medicamentos, pra depois se começara pesquisa no ser humano... Agora, especificamente aqui, nós fazemos pesquisa de fase III pra cima né, porque nós não temos as pesquisas iniciais. Então, na fase III nós já temos resultados de outros países, já tem comercializado em outros países, então não são cobaias."

Houve um pesquisador que expressou uma certa indignação com a pergunta, dizendo: "Você acha que pesquisa só pode ser feita nos Estados Unidos?.... nós fazemos geralmente essas pesquisas já no que eles chamam de fase III, fase IV. Nos Estados Unidos fazem fase I, fase II. A observação experimental de uma droga, pela primeira vez no ser humano, étudo feito lá. ... que eles fazem em, em voluntários que sabem que tão correndo risco de vida, etc. Pois bem, aí... isso a gente não faz. Vocês não querem que faça nem fase III, nem fase IV?"

Os pesquisadores enfatizaram a necessidade de uma melhor compreensão do conceito de cobaia para que as pessoas possam compará-lo aos sujeitos de pesquisa. Todos eles tentaram definir o que é cobaia. Segundo eles, o uso desse termo é pejorativo e deveria ser comparado com outras realidades, além da pesquisa clínica: "acho que a história de cobaias é mais um tom, digamos assim, mais pejorativo. ... quando entram no estudo, elas [mulheres] têm um benefício de estar recebendo uma medicação que não tem nenhum custo e fazendo uma série de exames, não é? ... desde quando tenha base científica eu não vejo por que usar o termo cobaia. "ou, "O médico, quando receita, ele está fazendo do seu paciente, cobaia. Se a interpretação que as pessoas dão para uma investigação informada do efeito de uma droga, imediatamente categoriza o objeto da ação como cobaí... Você é uma cobaia todo dia que você tá comendo comida tratada. Tá sendo cobaia de quem? Tá sendo cobaia da indústria que tá botando isso no mercado pra ver se não mata ninguém. Você tá comendo frango todo dia encharcado de estrogênio. Você tá sendo cobaia. Cobaia de quem? Eu te digo: não é de um médico. Tásendo cobaia da indústria de alimentos."

Os pesquisadores também criticaram a maneira como a mídia se posiciona frente ao assunto e enfatizaram a necessidade de se fazer pesquisas com seres humanos porque não se pode ter a certeza dos resultados baseando-se apenas nas pesquisas em animais. Além disso, mesmo que um produto tenha 
HARDY E ET AL.

sido testado em humanos de outros países, deve-se testar aqui também, porque as reações podem ser diferentes. "Não é como o jornal fala que as brasileiras estão servindo de cobaias para as americanas ou européias, de países mais desenvolvidos. Então a gente tem que explicarisso, que as diferenças regionais são muito importantes e que é indispensável que antes de se lançar uma medicação no Brasil, que as brasileiras também participem desse tipo de estudo". "A experimentação tem que ser feita emserhumano, porque não podemos extrapolar - que se faz em outras espécies não humanas ou mesmo em algumas sub-humanas [?]... o mais clássico é a história da talidomida, não é?"

Dentre as mulheres, dois terços [I I] disseram que sujeitos de pesquisa não podem ser considerados cobaias. As razões para isso incluíram os princípios de liberdade de escolha e os benefícios envolvidos: "Se você tá aceitando, eu acho que você não é uma cobaia. Se você tá aceitando é porque você quer passarporaquilo, porque tátendo necessidade, você tá precisando ouvocê tá com curiosidade de passarporaquilo. Eu não acho que isso seja cobaia."

Ao defender a opinião de que sujeitos de pesquisa não são cobaias, as mulheres enfatizaram que estas últimas não possuem liberdade de escolha: "Acho que cobaia seria aquela coisa assim, que a pessoa era obrigada a fazer, mas como a gente teve opinião, opção de escoIher, então eu não me sinto uma cobaia, porque cobaia pra mim são os ratos, porque os ratos, eles pegam, colocam no laboratório, então, aquilo ali é cobaia; aquilo não sai de lugar nenhum, né?"

Também apareceu entre as mulheres, assim como já relatado para os pesquisadores, a idéia de que os sujeitos não são cobaias porque as pesquisas são realizadas em fases iniciais com animais, o que diminui os riscos para o ser humano: "... você faz aquele remédio, você tem que testar aquele remédio para verse ele é eficaz. Geralmente eles testam em animais essas coisas. A partir do momento, euacho, que eles colocam no ser humano, eu acho que ele já foi testado, já foi feita várias pesquisas antes."

Entretanto, quatro mulheres afirmaram que os riscos envolvidos em pesquisas com seres humanos são suficientes para caracterizar os sujeitos como cobaias: "São cobaias porque, afinal de contas, as pessoas estão testando uma medicação pra ver se ela realmente vai dar certo ou não, pra ver se vai haver alguma contra-indicação".

As defensoras dos direitos das mulheres foram as que mais expressaram preocupação com o termo "cobaia" e o princípio de voluntariedade. Para elas, "cobaia é um termo complicado porque se supõe uma relação onde não tem nenhuma possibilidade de escolha, onde não se tem decisão, é, onde você não tem nenhum controle sobre aquilo, quer dizer, a gente sempre imagina o ratinho de laboratório."

Somente duas defensoras declararam que um sujeito de pesquisa não pode ser considerado cobaia, desde que ele consente e participa de forma consciente. Também mencionaram o fato de que as pesquisas realizadas no Brasil oferecem menor risco, por já terem sido realizadas em outros países: "Olha, acho isso uma bobagem, né. Principalmente porque todas as vezes que eu ouvi esse tipo de coisa, foi em relação aos medicamentos que já tinham sido pesquisados, inclusive fora do Brasil, e que estava sendo feito um estudo da situação local. Então eu não posso entender como é que, por exemplo, as nossas mulheres são cobaias de um determinado anticoncepcional, por exemplo, e as americanas, as hindus e as francesas não são. Então, écerto experimentarláfora enão écerto experimentar aqui?"

Entretanto, seis outras consideraram que, mesmo que o sujeito seja informado e dê o seu consentimento para participar de uma pesquisa, ele estará "sendo usado", e isto é o que o caracteriza como cobaia. Para elas, a única diferença é que ele está aceitando ser cobaia: "ele tem que ter clareza que ele está sendo sujeito de um experimento, acho que é cobaia do mesmo jeito, só que ele tem clareza de que é cobaia, entendeu?... acho que tem pessoas que estão disponiveis pra participar disso ou não, mas não deixa de ser cobaia"; "Ah, eu acho que ele sempre é uma cobaia, né? Assim, que a gente sempre é uma cobaia. Você sempre vai ter uma posição que ésempre desigual, né? Eque tem sempre alguém que sabe mais, né?"

Assim como os pesquisadores, também foi geral a colocação das defensoras sobre o termo "cobaia" ser utilizado em sentido pejorativo: "É, essa é uma expressão popular, acho isso muito popular, tudo que é experimentado, as pessoas são as cobaias. Qualquer coisa que é testado pela primeira vez, as pessoas chamam cobaia. A expressão é muito pejorativa, né".
Uma dessas entrevistadas referiu também a dificuldade de compreensão do termo: "Eu nem entendo direito o significado da palavra cobaia, a etimologia. Se cobaia implica nessa coisa de alguém que é submetido. Porque eu acho que você pode ser submetido a ..., que é uma posição passiva, no sentido de que você vai responder, você vai e seu corpo vai responder, alguém vai monitorar e você necessariamente não está numa posição de completa [liberdade de direito] é, sei lá, está em desprovimento dos seus direitos como cidadão, do direito de querer parar, do direito de quererentender..."

A maioria das defensoras referiu que a luta em defesa dos direitos das mulheres considera necessário fazer pesquisas, mas que se deve levar em conta o respeito pelo ser humano. Uma delas referiu que a grande maioria das brasileiras que participam como sujeitos de pesquisas são pessoas pouco esclarecidas, que nem sempre têm condições de entender, de fato, o que estão fazendo: "Eu acho que o problema nosso, todo, éque nós vivemos num país com muito pouca instrução; as pessoas têm muito pouca formação, né? Conhecem muito pouco o seu corpo, dominam muito pouco a questão da saúde, então elas, muitas vezes, podem ser facilmente manipuladas, né?"

\section{Discussão}

O primeiro elemento que chama a atenção em nossos resultados é a mínima diferença entre pesquisadores, mulheres e defensoras quanto à dificuldade em explicar o que é pesquisa. Esperava-se que os pesquisadores tivessem esse conceito perfeitamente claro, já que em teoria, para fazer pesquisa deveriam ter uma definição muito precisa do que se está fazendo. Resultou surpreendente que as explicações mais apropriadas foram propostas por defensoras e não por pesquisadores. Isto pode ser reflexo de que os investigadores, muitas vezes chefes de departamentos ou de serviços, não foram preparados para esse papel e não receberam formação em métodos de pesquisa e, além disso, têm muitas outras atribuições. Por isso, delegam a maior parte das responsabilidades pelo desenvolvimento de uma pesquisa a outros, geralmente, médicos que trabalham nos ambulatórios de planejamento familiar, sem necessariamente possuir pós-graduação ou uma boa formação em métodos de pesquisa ${ }^{17}$. 
As respostas dos participantes que conseguiram explicar o que entendiam por pesquisa apontaram aspectos coerentes com diferentes definições encontradas na literatura: promoção dos avanços no conhecimento científico ${ }^{18 ;}$ descoberta do que ainda não foi dito ${ }^{19}$; busca de soluções para problemas específicos ${ }^{20}$; avanço na direção de novos medicamentos ${ }^{21}$; corroboração ou rejeição de algum conhecimento pré-existente ${ }^{22}$; realização concreta de uma investigação planejada, de acordo com as normas científicas ${ }^{23}$.

Apesar da coerência nas explicações do que é pesquisa, cada grupo atribuiu valores diferentes ao conceito: os pesquisadores valorizaram a necessidade de evoluírem em seus conhecimentos, as mulheres valorizaram os benefícios que a pesquisa traz e as defensoras preocuparam-se com a possibilidade de diminuir riscos e aumentar benefícios. Isso parece confirmar o fato de que pessoas com aprendizagens e vivências diferentes sobre um mesmo assunto tendem a formar conceitos distintos sobre ele $24: 25$. Embora possa haver um referencial comum a todos, a interpretação individual pode variar conforme a abrangência de seus atributos e a situação na qual é utilizado ${ }^{25}$.

Com relação ao termo "cobaia", os pesquisadores tenderam a rejeitar que os sujeitos de pesquisa o fossem, ressaltando a autonomia deles (através do consentimento informado) como garantia da voluntariedade. Além disso, disseram que, no Brasil, os estudos não incluem as fases iniciais da experimentação clínica, mas sim o estudo de produtos já comercializados em outros países e, por isso, os sujeitos brasileiros não poderiam ser considerados cobaias. Isto parece sugerir que os sujeitos que participam das fases inicias do estudo de uma nova droga contraceptiva poderiam ser considerados cobaias.

As mulheres, no geral, não se consideraram cobaias, pelo contrário, sentiram-se privilegiadas em participarem como sujeitos, alegando que, além de usarem gratuitamente o contraceptivo que escolheram livremente, contribuíram com o desenvolvimento de uma pesquisa. Também mencionaram o fato de que as fases iniciais das pesquisas são realizadas com animais, o que diminui os riscos para elas.

Foi diferente a posição das defensoras comparada à dos pesquisadores e mulheres (que já haviam sido sujeitos de pesquisa). Para as defensoras, ao contrário dos pesquisadores, os sujeitos são cobaias, apesar do consentimento. Com relação às mulheres, a postura das defensoras foi, de certo modo, paternalista quando, em defesa de seus direitos, duvidaram de sua capacidade de decidir se queriam ou não ser sujeitos de pesquisa. As mulheres, entretanto, rejeitaram essa postura, reafirmando insistentemente sua autonomia e voluntariedade. A diferente posição assumida pelas mulheres em relação às defensoras pode estar relacionada ao fato de que a experiência ao participar como sujeitos de pesquisa colocou-as mais expostas ao "saber médico" e à influência dos pesquisadores.

Embora se aceite a afirmação das mulheres quanto à sua autonomia em decidir, não se pode deixar de lembrar que elas valorizaram os benefícios recebidos. Isto leva a questionar se a decisão de participar como sujeito teria incluído uma escolha racional, baseada também em valores de direitos e de cidadania. De qualquer maneira, há que se enfatizar que as mulheres reagiram negativamente quando se sentiram comparadas a cobaias. Provavelmente, o sentido pejorativo atribuído ao termo tenha atingido diretamente sua auto-estima, ao se verem comparadas a seres que, segundo elas próprias, não possuem a capacidade de pensar e raciocinar.

De certa forma, esse sentido pejorativo atribuído popularmente ao termo "cobaia" tem sido bastante difundido em artigos de jornais, cujos títulos associam o termo a aspectos negativos de pesquisas com seres humanos, como: "Brasileiras foram cobaias de anticoncepcional americano"|3; "Entre ciência e terror"2; "O Brasil já tem mais de 500 mil cobaias"27; "Ratos e Homens" 28. Títulos como esses e tantos outros semeIhantes lançam dúvidas sobre o respeito dos pesquisadores aos princípios éticos. Isto tem provocado reação e repúdio por parte de muitos pesquisadores que entendem essas mensagens como inconseqüentes e destrutivas ao seu trabalho ${ }^{29}$, além de desmerecerem a contribuição dos voluntários no avanço do conhecimento científico ${ }^{28}$.

O discurso difundido pela mídia, além de refletir os significados vigentes, também faz parte do processo pelo qual as pessoas constroem significados ${ }^{30}$. Neste sentido, a mídia tem desempenhado um papel extremamente relevante na popularização da discussão de temas científicos e, justamente por isso, também vem exercendo forte influência na interpretação de informações sobre a participação de seres humanos em pesquisas na área da regulação da fecundidade. Barroso e Corrêa ${ }^{5}$ encontraram 9 I artigos sobre investigação com contraceptivos na imprensa brasileira, entre junho de 1984 e fevereiro de 1988. Isto confirma a participação da mídia nas discussões sobre as atividades dos cientistas e talvez até na popularização de termos como "pesquisa" e "cobaia". A popularização pode ter contribuído para que os termos assumissem diferentes significados, sugerindo que as críticas aos pesquisadores podem ser o resultado dessas diferenças.

$\bigcirc$ fato é que essas discussões têm mobilizado diversos setores da sociedade em torno da informação científica como um direito de cidadania, fundamental para o controle social do conhecimento e da correção ética. A difusão do termo "cobaia", para qualificar os sujeitos de pesquisa, pode servir de estímulo para que se coloque maior cuidado ético na implementação de pesquisas. Seguramente que o termo "cobaia" não se justifica na maior parte dos estudos realizados hoje no Brasil, mas sua difusão, com objetivo muitas vezes sensacionalista, pode ter um efeito final positivo, porque seu significado coloca uma grande responsabilidade nos ombros dos pesquisadores, e serve de lembrança constante para terem o máximo de cuidado ao agir de forma eticamente correta nas pesquisas com seres humanos.

Os resultados deste estudo revelaram, portanto, a dificuldade dos pesquisadores, sujeitos de pesquisa e defensoras dos direitos das mulheres em definir o que é pesquisa e as controvérsias sobre os sujeitos serem cobaias ou não. Por isto, é provável que os achados aqui discutidos também sejam úteis para pesquisadores de outras áreas que também se defrontam com essas dificuldades.

\section{AgradeCIMENTOS}

As autoras agradecem à Organização Mundial da Saúde pelo apoio financeiro proporcionado, bem como aos pesquisadores e a todas as mulheres e defensoras que dedicaram seu tempo para responder as nossas questões.

Conflito de interesse: não há. 


\section{SUMMARY \\ RESEARCH ON CONTRACEPTION: OPINION OF RESEARCHERS, SUBJECTS AND ADVOCATES OF WOMEN RIGHTS}

OBIECTIVE. To survey the opinion of researchers, women - subjects of researchand of advocates of women's rights about the meaning of "research" and "guinea pigs". Methods: Researchers (I I), women (I8) and advocates (10) were interviewed. The study was qualitative and a thematic analysis was carried out.

RESULTS. Participants experienced difficulty to explain what research meant and some were unable to do so. For the researchers and most of the women, subjects are not guinea pigs, because they have freedom of choice. Most of the advocates, however, said that subjects are guinea pigs, even when they consent to participate in a study.

CONCLUSIONS. The difficulty experienced by researchers when explaining the meaning of research was surprising. The different opinions about "guinea pig" reflect the controversy about its meaning in research. Certainly the expression "guinea pig" does not apply to all studies however the different meanings identified should make researchers cautious about the ethical issues involved in their studies. [Rev Assoc Med Bras 2004; 50(4): 451-6]

KeY wORDS: Research. Ethics. Human guinea pigs. Contraception.

\section{REFERÊNCIAS}

I. Ávila MB, Corrêa S. O movimento de saúde e direitos reprodutivos no Brasil: revisitando percursos. Católicas por el Derecho a Decidir. [citado 28 nov 2002]. Disponível em: http:// www.geocities.com/catolicas/articulos/ dersex/omovim.htm.

2. Faúndes A, Diaz J, Aguinaga H, Pinho Neto S, Mello CR, Araújo F. Estudo brasileiro com os implantes anticoncepcionais NORPLANT ${ }^{\circledR}$ até três anos de uso. Femina 1992; 20(3): 196-205

3. Asociación Médica Mundial. Declaración de Helsinki de la Asociación Médica Mundial. [citado 9 fev 200l]. Disponível em: http:// www.wma.net/s/policy/l7-c_s.html.
4. Oliveira F, Mota JAC. Dossiê bioética e as mulheres. In: Rocha MIB, Araújo MJO. Saúde da mulher e direitos reprodutivos. Dossiês200 I. Rede Feminista de Saúde. [citado 3 abr 2002]. Disponível em: http://www. redesaude.org.br/dossies/body dossiessr.html.

5. Barroso C, Corrêa S. Servidores públicos versus profesionales liberales: la política de la investigación sobre anticoncepción. Estudos Sociológicos 1991; 9(25):75-104.

6. CMB/AMe a esterilização da mulher. Jornal do Comércio, Manaus. 1986 ago 31. Seção: Cidade. p. 12

7. Paciente leiga usa cápsula. Jornal do Comércio, Manaus. 1986 ago 29. Seção: Cidade.

8. Blaney CL. Informed consent plays key role. Network 1994; I5(I):22-5.

9. Pitanguy J. Feminist politics and reproductive rights: the case of Brazil. In: Sen G, Snow RC, editors. Power and decision. The social control of reproduction. Boston: Harvard School of Public Health; 1994. p. I0 I-22.

10. Brasil. Ministério da Saúde. Conselho Nacional de Saúde. Câmara Técnica de Medicamentos. Resolução Normativa 1/78, 30 de agosto 1978. Dispõe sobre o estabelecimento de uma sistemática da experimentação terapêutica, bem como de todos os itens que devem ser abrangidos nas suas diversas etapas. Diário Oficial da República Federativa do Brasil, Brasília, DF, I 16(198):16746, 17 out 1978. Seção I, parte I.

I I. Brasil. Ministério da Saúde. Secretaria Nacional de Vigilância Sanitária. Divisão Nacional de Vigilância Sanitária de Medicamentos (DIMED). Portaria n ${ }^{\circ}$ 16, de 27/I I/8 I. Dispõe sobre a instituição padronizada do Termo de Conhecimento de Risco para pesquisas com medicamentos não registrados pela DIMED, ou com indicação ainda não aprovada, ou em produtos importados ainda não analisados pela DIMED. Diário Oficial da República Federativa do Brasil, Brasília, DF, II9(235):23745, 14 dez 1981. Seção I.

12. Brasil. Ministério da Saúde. Conselho Nacional de Saúde. Resolução n 01/88 de 13/6/88. Dispõe sobre a aprovação das normas de pesquisa em saúde. Diário Oficial da República Federativa do Brasil, Brasília, DF, I26(I I0): 107|3, | 4 jun 1988. Seção |.

13. Brasileiras foram cobaias de anticoncepcional americano. Diário Popular. 13/12/1990.

14. Madeira L. Experiência em universidade causa esterilidade em mulher. Jornal $O \mathrm{Dia}$, Rio de Janeiro. 199I set 29

15. Hardy E, Bento SF, Osis MJD, Hebling EM. Consentimento informado na pesquisa clínica: teoria e prática. Rev Bras Ginecol Obstet 2002; 24(6):407- 12.
16. Wolcott HF. Transforming qualitative data: description, analysis, and interpretation. Beverly Hills: Sage Publications; 1994.

17. Hardy E. Factors often not considered before a multicenter trial is started. Clin Pharmacol Ther 1996; 60:121-3.

18. Goldenberg S. Orientação normativa para elaboração de tese. Acta Cir Bras 1993; (Supl I): I-24.

19. Eco H. Como se faz uma tese. São Paulo: Perspectiva; 1989

20. Booth WC, Colombs GG, Williams JM. A arte da pesquisa. São Paulo: Martins Fontes; 2000.

21. Scheffer M. No país das cobaias. Folha de São Paulo, São Paulo. 2001 ago 10. Seção: Opinião. p.A3.

22. Clarck OAC, Castro AA. A pesquisa. In: Castro AA. Planejamento da pesquisa. São Paulo: AAC; 200 I. [citado 200 I jan I5]. Disponível em: http://www.evidencias.com/lv4.htm.

23. Ruiz JA. Metodologia científica: guia para eficiência nos estudos. $4^{a}$ ed. São Paulo: Atlas; 1996.

24. Araújo FMBG, Witter GP, Martins LS, Ribeiro $M L$, Giacometti MM. Conceito de pesquisa: um estudo exploratório comparando perspectivas de pesquisadores e leigos. Estudos de Psicologia. Campinas, 1988; 5(I):53-73.

25. Gargantini MB, Moreira SRG, Foresti SMS. Conceito de pesquisa: opinião de mestrandos e de pesquisadores de diferentes áreas de formação. Transinformação 1996; 8(2). [citado 2002 fev 27]. Disponível em: http:// www.puccamp.br/ - biblio/gargantini82.html.

26. Entre ciência e terror. Folha de São Paulo, São Paulo. 200 I jul 31. Opinião. Seção: Editoriais. p.A2.

27. Leite F, Silva JC. Brasil já tem 500 mil 'cobaias' humanas. Folha de São Paulo, São Paulo. 2001 jul 27. Seção: Campinas. Em nome da Ciência. p.C5.

28. Nucci GD. Ratos e homens. Folha de São Paulo, São Paulo. 200 I jul 30. Opinião. Seção: Painel do Leitor. p.A3.

29. Sabbatini RME. "Cobaias humanas" e experimentação médica. [citado 2001 nov 23]. Correio Popular, Campinas. 1999 jul 2. Disponível em: http://home.nib.unicamp.br/ $\sim$ sabbatin.

30. Citeli MT. A reprodução humana na pauta dos jornais brasileiros. In: Oliveira F, Galvão], Greenhalgh L, Rios LF, Pazello M, Citeli MT, et al. Olhar sobre a mídia. Belo Horizonte: Mazza Edições; 2002. p. I84-2II.

Artigo recebido: 08/07/03 Aceito para publicação: 17/03/04 